\title{
Toward a New Understanding of Ethnic/Racial Settings for Ethnic/Racial Identity Development
}

\author{
Moin Syed, University of Minnesota, USA \\ Linda P. Juang, University of Potsdam, Germany \\ Ylva Svensson, University of Gothenburg, Sweden \\ In press \\ Journal of Research on Adolescence \\ $02 / 14 / 18$
}

Contact:moin@umn.edu 


\begin{abstract}
The purpose of this conceptual paper is to advance theory and research on one critical aspect of the context of ethnic/racial identity (ERI) development: ethnic/racial settings, or the objective and subjective nature of group representation within an individual's context. We present a new conceptual framework that consists of four dimensions: 1) perspective (that settings can be understood in both objective and subjective terms); 2) differentiation (how groups are defined in a setting); 3) heterogeneity (the range of groups in a setting); and 4) proximity (the distance between the individual and the setting). Clarifying this complexity is crucial for advancing a more coherent understanding of how ethnic/racial settings are related to ERI development.
\end{abstract}

Keywords: ethnic identity; racial identity; ethnic density; settings; context; heterogeneity; diversity 
Ethnic/racial identity has been solidified as a core developmental construct, as reflected in the recent special issue of Child Development reporting on the work of the Ethnic and Racial Identity (ERI) Study Group (Rivas-Drake, Seaton, et al., 2014; Rivas-Drake, Syed, et al., 2014; Schwartz et al., 2014; Umaña-Taylor et al., 2014). That collection of articles made clear that we have gathered a great deal of research on "basic” processes of ERI (i.e. its developmental course and psychological correlates). Although this work was critically important for the field, their focus on basic process betrays the ongoing calls for greater consideration of a contextualized account of ERI development (Verkuyten, 2016; Way \& Rogers, 2015), as well as the view that contextualized development should, itself, be considered “basic” (Gjerde, 2004). This limitation was addressed, in part, through a second special issue of Child Development focused explicitly on context and ERI (Seaton, Quintana, Verkuyten, \& Gee, 2017). Those articles made important contributions to understanding the relational context of ERI, in particular (e.g., Santos, Kornienko, \& Rivas-Drake, 2017), but the collection did not include any serious examination of how context itself is conceptualized.

The purpose of this article is to advance theory and research on one critical aspect of the context of ERI development: ethnic/racial settings, which we define as the objective and subjective nature of group representation within an individual's context. Settings are typically conceptualized as places in which activities and interpersonal interactions occur, such as the home, classroom, neighborhood, and city (Bronfenbrenner \& Ceci, 1994; Raudenbush \& Sampson, 1999). We extend this concept by arguing that ethnicity/race serves as a setting for development, defined not only in terms of its physical location (e.g., home, school) but in the prevalence and nature of ethnic/racial representation within that particular setting. To date, research on ERI and ethnic/racial settings has been highly inconsistent and has not adequately 
engaged with the complexity with which settings must be conceptualized and measured. As such, in this paper we establish a new multi-dimensional conceptual framework for how to study ethnic/racial settings. In doing so, we seek to incorporate the multitude of relevant terms that are used in the literature, including concentration, density, diversity, and heterogeneity. All of these terms and concepts are included in our framework and are discussed further when presenting each dimension.

Importantly, although we center the framework on its relevance for ERI research, our focus is on how to conceptualize ethnic/racial setting themselves, independent from how they would be put to use in substantive research. Indeed, ethnic/racial settings are a contextual factor with great relevance to other aspects of adolescent development, such as discrimination, schooling, peer relations, and neighborhood influences (see Graham, 2016; van der Meer \& Tolsma, 2014). Moreover, although much of the ERI research has been conducted in the U.S., there is also a substantial body of relevant work in Europe, where there has been a tremendous increase in immigrant and refugee populations. Many countries that were once viewed as homogenous (e.g., Sweden) are now quite ethnically diverse, and thus ERI research has become increasingly relevant and prevalent. Inclusion of European studies has important implications for our framework, as the differences between countries and cultures render some U.S.-based understandings of how to conceptualize ethnic/racial settings inappropriate. We provide specific examples of this issue in our discussion of the framework. Accordingly, this new framework will be of broad use for advancing research on adolescence.

At the same time, we are mindful that researchers in other areas of psychology, sociology, and related fields have written extensively about the complexities of ethnic/racial settings. This research has brought attention to the many different dimensions of ethnic/racial 
settings (e.g., Ashmore, Deaux, \& McLaughlin-Volpe, 2004; Graham, 2016; Sadler \& Devos, 2017; van der Meer \& Tolsma, 2014). Nevertheless, to our knowledge there has not been a concerted effort to pull together a set of core dimensions of ethnic/racial settings and how they might fit together into a single framework. As discussed throughout the paper, the lack of such a unified framework seriously compromises our ability to synthesize the existing literature to develop generalizable knowledge. Thus, our aim is to build upon and consolidate past contributions to help inform more planful and cumulative research in the future.

\section{Context and ERI: The Theoretical Relevance of Ethnic/Racial Settings}

While there are a variety of models of ERI (see Umaña-Taylor et al., 2014; Verkuyten, 2016), Phinney’s (1990) developmental model of ERI continues to be highly influential in the field. The developmental model reflects a confluence of two major identity theories: Marcia's (1966) identity status model (an interpretation of Erikson's (1968) theory of identity), and social identity theory (Tajfel \& Turner, 1986). All of these theories highlight the important role of context in general, and ethnic/racial settings in particular. Interestingly, however, they do so in different ways. Erikson's theory, and to a lesser extent Marcia’s, indicates that the development of domain-specific identities (e.g., ethnicity, occupation, religion) will be highly reliant on the opportunities for those identities to develop. Translating this idea to the study of ERI would suggest that individuals living in contexts with many other co-ethnic members would lead to a stronger sense of ERI, as the greater representation would provide a broader array of identityrelevant resources (e.g., co-ethnic peers, community events, institutional representation). This connection can clearly be seen in how the construct of exploration is assessed in the developmental model, inquiring about the frequency with which individuals engage in behaviors such as participating in cultural events and talking with people about their background (e.g., 
Roberts et al., 1999). In short, the developmental model leads to the prediction that individuals living in environments dense with co-ethnics would develop stronger ethnic/racial identities.

In contrast to the Eriksonian approach to identity, social identity theory suggests something quite different. Importantly, social identity theory (Tajfel \& Turner, 1986) and the related self-categorization theory (Turner, Hogg, Oakes, Reicher, \& Wetherell, 1987) are much more specific than Eriksonian theory about the nature and consequences of both situational and societal contexts for ERI processes (see Verkuyten, 2016, for an excellent overview). Among other processes, this approach broadly emphasizes how social identities (e.g., ERI) become salient in response to the representation of different groups as well as their relative status within a setting. In particular, settings in which individuals are in the minority (in terms of numerical representation or social power, which often go together at the societal level) can activate awareness of their ethnicities (Sellers et al., 1998; Tajfel \& Turner, 1986; although this can depend on many other factors, see Verkuyten, 2016). Because the meaning and significance of ethnicity, as a social identity, is embedded in an unequal societal power structure, the situational awareness can be associated with perceptions of threat, thus leading individuals to enact one of many potential identity management strategies. Most germane to the present paper is the strategy of increased group identification to develop connectedness with others and boost their sense of self-worth. In short, from a broad social identity perspective, contexts with relatively few coethnics will be associated with stronger ethnic/racial identities.

Our purpose here is not to take side with one theoretical account or the other, but rather to suggest that the inconsistencies in studying ethnic/racial settings severely restricts our understanding of ERI development from any theoretical accounts researchers choose to draw upon (see White, Knight, Jensen, \& Gonzalez, 2017). Moreover, there are two ways in which 
ethnic/racial settings may be relevant for ERI, each of which is rooted in different theoretical arguments. On the one hand, ethnic/racial settings may be implicated in the development of ERI as a person-level construct, as articulated in the developmental model of ERI, and therefore variations in ethnic/racial settings would be associated with variations in the mean levels, or strength of ERI. On the other hand, variations in ethnic/racial settings may serve as a moderator, within for example a risk and resilience framework (e.g., García Coll et al., 1996), and therefore would be associated with variations in how ERI is related to psychosocial and developmental sequelae, such as psychological distress, positive well-being, or academic adjustment (see metaanalysis by Rivas-Drake, Syed, et al., 2014). Research on ERI and ethnic/racial settings has examined both conceptualizations, with mixed results. Studies have found differences in levels of ERI but not links to mental health (Umaña-Taylor, 2004), differences in links to mental health but not in levels (Juang, Nguyen, \& Lin, 2006), and no differences in levels or developmental trajectories (Syed, Azmitia, \& Phinney, 2007). These equivocal findings have led to an incoherent understanding of the relation of ethnic/racial settings with both levels and correlates of ERI.

In sum, there is extensive variability in theoretical guidance, empirical assessment, and subsequent findings. Not only that, ethnic/racial settings are operationalized in inconsistent ways. All told, one of the major barriers to clearly understanding the relation between ERI and ethnic/racial settings is the lack of a conceptual framework for how to study the setting itself. That is, although there are numerous theoretical frameworks that include ethnic/racial settings as a factor in a larger model to understand specific outcomes (e.g., social disorganization theory; Kubrin \& Weitzer, 2003), those frameworks do not conceptualize ethnic/racial settings in their 
own right. Given the prominence of the concept, there is a great need to develop a strong framework for how to assess ethnic/racial settings to guide future work.

\section{Introducing a New Dimensional Framework for Studying Ethnic/Racial Settings}

While the concept of ethnic/racial settings may seem rather straightforward, it involves a high degree of unappreciated complexity. A coherent understanding of how ethnic/racial settings are related to ERI development must account for this complexity. To be sure, several conceptual review papers have discussed some of the complexities involved in ethnic/racial settings (Ashmore, et al., 2004; Graham, 2016; van der Meer \& Tolsma, 2014), but each one only addresses some dimensions while omitting others. Based on our synthesis of the literature, the new framework consists of four distinct but interrelated dimensions (Table 1): 1) perspective, meaning that ethnic/racial settings can be understood in both objective and subjective terms; 2) differentiation, referring to how the ethnic group of reference is defined in a setting; 3) heterogeneity, the degree of variation, or diversity, of different ethnic groups in the setting, and 4) proximity, the distance between the individual and the setting that is assessed.

As noted at the outset of this paper, we define ethnic/racial settings as the objective and subjective nature of group representation within an individual's context. This definition is more expansive than how ethnic/racial settings have been previously defined in the literature (e.g., Bécares et al., 2012). Our more expansive definition is meant to better capture some of the complexities inherent in the notion of ethnic/racial settings , namely the four dimensions of the proposed framework. First, the definition includes both objective and subjective aspects of group representation, indicating that it is important to examine additional features of the context (e.g., perspective and heterogeneity) beyond numerical representation (i.e. concentration). Second, the definition specifies group representation, rather than co-ethnics, in-groups, or ethnic minorities, 
in order to accommodate flexibility in how groups are defined in a particular context (e.g., differentiation). Finally, we define the spatial referent as “an individual's context” to allow for measurement at different scales (vs. the more restrictive "area” used by Bécares et al. 2012; e.g., proximity).

Importantly, our definition of ethnic/racial settings --which incorporates all four dimensions--is meant to highlight how the dimensions are always inter-related; that conceptualizing and measuring one dimension also requires a consideration of the others, and when measures are selected, the other dimensions are always at least implicitly defined. For example, Brown (2017) examined how the proportion of Latino students and teachers within schools was associated with students' ERI development. This study relied on an objective assessment of group representation (i.e., school records), defined the referent group at the panethnic level, implicitly defined heterogeneity in binary terms (Latino or not), and specified the school as the scale of the context. Being clear about the definition of ethnic/racial settings and its constituent dimensions is critical, as there is currently no consistent use of terms within the literature, which we highlight when discussing each dimension. One major goal of the current paper is to encourage researchers to be more conscious and intentional of measurement decisions and definitions that they may not even fully realize they are making. Doing so serves the broader goal of developing a more cumulative science of ethnic/racial settings and ERI development.

The remainder of this paper is organized in four main sections. First, we will describe each dimension in detail, including methods of assessment and conceptual and empirical links to ERI. Because ethnic/racial settings have not been extensively studied in relation to ERI, and due to the relevance of ethnic/racial settings to other topics in adolescent development, we bring in literature on other topics such as how density relates to interethnic peer relations, acculturation, 
and experiences of discrimination. Not only are these factors all relevant to ERI, but also learning from the methods used in these areas of research will be beneficial for the future of ERI research. The interconnectedness among these areas of study also implies that our framework will be useful for researchers studying topics beyond ERI. Second, we describe the framework as a whole, and explore the interplay of the four dimensions. Given extant research we try to answer the question of how these dimensions interact and combine to influence ERI. Third, we show how our proposed framework can aid future ERI work and have implications for both theory and empirical research. In doing so we present some empirical studies that illustrate the methodological approaches that our framework calls for. Finally, we end with a conclusion and some future directions for ethnic/racial settings within the ERI framework.

\section{Dimension 1: Perspective}

At the core of our new framework is the idea that there are multiple perspectives that can be used to understand ethnic/racial settings. The majority of existing research is based on objective measures of settings. Objective measures are widely used and often referred to as concentration, density, or proportion of individuals from a particular ethnic/racial group (e.g., Brown, 2017; Syed, et al., 2007; White et al., 2017). These measures are “objective” because they are based on official records, such as census or register data, and provide a description of the setting in terms of relative representation of different groups. Although these data are frequently based on individuals’ self-reported ethnicities, and thus involve some level of subjectivity, they imply that all individuals within the setting perceive and interpret the setting in the same way, and even that individuals have some awareness of the levels of density within their settings (Bellmore, Nishina, Witkow, Graham, \& Juvonen, 2007). Using this approach, researchers can simply look up the appropriate figures to have an understanding of the setting. 
Consequently, objective measures are researcher-driven approaches to understanding ethnic/racial settings, and represent the most common, default approach.

However, the sole use of the objective approach is insufficient, as ethnic/racial settings can also be understood subjectively. Subjective settings are how individuals uniquely perceive their settings. Indeed, the same "context" is perceived differently for individuals who are a part of it (Syed, 2010). The flexibility of subjective perspectives affords several strengths that are not possible with objective measures. Questions such as "How do you describe the ethnic composition of your neighborhood" (Phinney, Ferguson, \& Tate, 1997) and "How many different cultures are there in your neighborhood?" (Stevenson, McNeil, Herrero-Taylor, \& Davis, 2005) allow for individuals to themselves define their in-groups and out-groups, thereby circumventing the challenges associated with using official records that track only coarse groups. Moreover, these types of measures give room for relative comparisons based on prior experiences. For example, a student transitioning from a highly ethnically diverse high school might experience the university context differently than a student transitioning from a highly homogenous high school (Douglass, Yip, \& Shelton, 2014). Further, whereas objective measures of settings tell us something about the opportunities for intragroup or intergroup contact, meaningful contact may not be actually happening. Due to institutional barriers like tracking systems in schools, or social self-segregation (Graham, 2016), high density would not inevitably mean high integration over ethnic/racial lines (Sadler \& Devos, 2017). Including subjective measures, such as asking about the daily interactions with people of other ethnic groups, could give a more ecologically valid measure of the experience of the setting (Yip, Seaton, \& Sellers, 2010). Finally, aggregating individual-level subjective perceptions allows for multi-level assessments of settings that are nested within one another, such as students within classrooms 
within schools, or individuals within neighborhoods (e.g., Fauth, Roth \& Brooks-Gunn, 2007). As such, the contribution of perceptions of heterogeneity at multiple levels to variations in ERI could be easily examined.

Subjective measures also allow us to assess other aspects than the perceptions of relative group representation. Group power and status are important aspects of how ethnic minority youth experience their contexts (Kumar, Seay, \& Karabenick, 2015). Way and colleagues have argued that the subjective experience of the hierarchy between different minority groups in a context is more important than the relative group size (e.g. Way \& Rogers, 2015). Hierarchies of status can also exist within the same minority group depending on immigrant status and country of origin. Kumar et al. (2015) found that newly immigrated Arab students in the US were aware of their lower social status relative to other Arab groups, and struggled with the derogatory "boater” identity and the discrimination they experienced from more well-established immigrant groups.

In terms of ERI research, the relative contribution of objective vs. subjective measures remains unknown, as the majority of the research has relied on objective measures (Douglass et al., 2014). Studies that used subjective measures have yielded inconsistent findings. For example, while Juang and Nguyen (2010) found that the subjective perception of neighborhood ethnic density was related to ethnic pride for Chinese Americans, Rucker and colleagues (2014) found no relation between the subjective experience of community racial density and racial centrality among African American youth. Other studies using subjective measures , have found higher levels of co-ethnics in a context to be related to stronger and more salient ethnic/racial identities (Yip, 2005).

Despite these inconsistencies, studies on topics other than ERI using both subjective and objective measures suggest that the subjective measures have higher explanatory value. In a 
study of neighborhood density and discrimination among Asian Americans, the subjective measure (perceived neighborhood density), but not the objective (percentage of Asians by zip code district), was predictive of discrimination (Juang \& Alvarez, 2011; see also Syed \& Juan, 2012; Yip et al., 2010). All of these studies, however, are limited in that objective and subjective perceptions of settings are not assessed at the same level of proximity, the third dimension in our model, so they are not always directly comparable (e.g., individuals’ perceptions of what constitutes their neighborhood may not map on to the area covered by a zip code). Moreover, not all studies indicate that subjective perceptions are more important than objective. For example, in a study of ethnically diverse high school students, both objective and subjective measures of school ethnic density predicted lower peer ethnic discrimination (Bellmore, Nishina, You, \& Ma, 2012). Thus, including both objective and subjective aspects of settings to fully understand the experience of that setting and its relevance for ERI, is essential.

\section{Dimension 2: Differentiation of the Group Context}

The second dimension of our framework, differentiation, refers to how the groups are defined and included in the setting. Most studies of ethnic/racial settings have focused on the proportion (percentage) of co-ethnic members. But how these co-ethnic members are defined varies across studies. Ethnic groups can be more or less specific in who is included (i.e., who is in the in-group). In the U.S. context, where race and ethnicity are salient and often-used concepts, differentiation refers to specific ethnic groups, pan-ethnic groups, racial groups, or most broadly, People of Color. In a study of ethnic discrimination and psychological distress, three levels of differentiation were included — ethnic-specific, pan-ethnic, and People of Color (Syed \& Juan, 2012). Results showed that when ethnic/racial settings mattered, it was most 
important when conceptualized more narrowly, as ethnic-specific, and least important when conceptualized more broadly, as People of Color.

Differentiation, however, is highly sensitive to the cultural context. The level of differentiation, for instance, depends on the distribution of the subgroups in the particular setting. If there are only a handful of specific ethnic groups in a school, differentiating by specific ethnic groups will not be feasible. More importantly, because the concepts of race and ethnicity (used in U.S. studies) are not as relevant in other societies, other aspects may be more salient as the basis for in-group definitions. For example, in Sweden there is support for an immigrant identity, where immigrant status is the commonality that binds a group together, regardless of ethnic background or nationality (Svensson, Burk, Stattin, \& Kerr, 2012). In highly diverse multicultural societies, differentiation of the group context has often meant a division between immigrants versus non-immigrants, where the immigrant group is defined and specified as part of a diaspora (Titzmann \& Silbereisen, 2009), non-Nordic immigrants (Svensson et al., 2012), non-western immigrants (Vervoort, Flap, \& Dagevos, 2010), or where specific immigrant groups are compared to each other or non-immigrants. These different ways of defining groups makes it difficult to draw conclusions across studies.

The appropriate group definition must always attend to these contextual variations but should also be closely tied to the specific research question. There is a strong consensus that ethnic/racial groups are historically and culturally created, maintained, and revised (Hochschild, 2005; Gjerde, 2004; Teo, 2009). This means that there is some flexibility, as well as arbitrarity, in the definition of ethnic groups. Accordingly, groups should be defined with respect to the particular research question. For example, a study of how ethnic/racial settings are related to ERI and Spanish language use in schools could reasonably make use of the pan-ethnic Latino 
category, whereas a study on ethnic/racial settings as related to ERI and the endorsement of specific Mexican cultural values (e.g., respeto; Ruvalcaba et al., 2015) would require a sample of Mexican-American participants. In each case the referent group that is assessed vis-à-vis the ethnic/racial setting is different, tailored to the specific research question.

\section{Dimension 3: Heterogeneity within the Setting}

The third dimension of the framework, heterogeneity refers to the range of different ethnic/racial groups in a given setting, from more homogeneous to more heterogeneous. A setting can thus vary both in the number of different groups represented and the relative proportion of each (e.g., Juvonen, Nishina, \& Graham, 2006). As a result, a setting could be highly ethnically dense, but low on ethnic heterogeneity when there are many co-ethnics but few other ethnic groups. Such is the case with "ethnic enclaves,” or regions within cities with a high proportion (high concentration) of a single ethnic group (e.g., Armenians in Los Angeles; Phinney, Romero, Nava, \& Huang, 2001). Graham (2016) used the term “structural diversity,” Sadler and Devos (2017) used “variety,” and van der Meer and Tolsma (2014) used “ethnic heterogeneity" to refer to this dimension. We prefer the term "heterogeneity" to accommodate the different group definitions that researchers might use (racial, ethnic, immigrant) and because the terms "variety” and “diversity” are vague and can often be misleading. Diversity is defined as variation, but it is sometimes used only to signify the presence of ethnic minorities in a setting. However, a setting such as a classroom that includes 70\% African American students and 30\% White students is not particularly diverse, as only two groups are represented. One could claim, however, that there is a high concentration of African American students. Just what exactly constitutes a diverse or heterogeneous context is difficult to say, but as we describe below, there are several methods that attempt to represent it. 
Heterogeneity is often assessed as the proportion of individuals in the majority (e.g., Whites) and minority (e.g., non-Whites). This simple assessment, however, is problematic as it erases variability within the minority group by lumping all of them into one category (Budescu \& Budescu, 2012). More useful measures of heterogeneity are different indices calculated to capture both the number of different ethnic groups in a setting as well as their relative sizes (see Budescu \& Budescu, 2012, for a detailed summary). Relative size is an important aspect of heterogeneity as it may be an indicator of an imbalance of power, status, and norm setting (Graham, 2016; van der Meer \& Tolsma, 2014). For instance, groups small in number perceive more discrimination (Benner \& Graham, 2013), an important factor related to ERI.

Simpson’s Diversity Index (Simpson, 1949) is the most commonly used measure for heterogeneity. It represents the probability that two randomly selected individuals in a context would be from different ethnic groups (Simpson, 1949). Herfindahl's index (Vervoort, Flap, et al., 2010), the ethnolinguistic fractionalisation index, which is calculated the same as Simpson's Diversity Index (Alesina, Devleeschauwer, Easterly, Kurlat, \& Wacziarg, 2003), and the heterogeneity index (Moody, 2001) are other heterogeneity indices measuring the number of different ethnic groups in combination with their relative proportions. Other indexes, like the Neighborhood Diversity Index (Maly, 2000), assesses the heterogeneity of one’s neighborhood in relation to the broader city (Massey \& Denton, 1988). The index is computed as the absolute value of the sum of differences between the percentage of each ethnic-racial group living in a particular census tract and the city as a whole, and is therefore an index of relative heterogeneity. Again, because a given context can range both in terms of the number of groups represented and the relative proportion of each, it is important to use these indices that take both into account, but 
also for researchers to be mindful of these features of the context when interpreting their findings (i.e., not just focusing on the index itself).

Results of studies linking ethnic and racial heterogeneity to ERI are mixed. For example, in a study of immigrant youth in Germany, heterogeneity, measured with the ethnolinguistic fractionalisation index, was related to participants' German national identities but not to their ethnic identities (Schachner, et al., 2016). Importantly, in Schachner et al.'s study they were able to disentangle the effect of proportion of immigrant versus heterogeneity of immigrants on identity. Oyserman and Yoon (2009) found that lower heterogeneity, measured with the Neighborhood Diversity Index, was associated with lower scores on ERI connectedness, awareness of racism, and embedded achievement among African American and Latino youth. Other studies have found no relation between heterogeneity and ERI; a study of Latino and African Americans found that classroom ethnic diversity, measured with the Simpson's Diversity index, was not significantly related to students’ private regard dimension of ERI (Graham, Munniksma, \& Juvonen, 2014). To reconcile these mixed findings, it is important to note that measures of heterogeneity are not assessed at the same level of proximity and some fuse different levels of proximity together (e.g., the Neighborhood Diversity Index measures relative heterogeneity of neighborhood to whole city). This again points to the tension that different dimensions of ethnic/racial settings are often implicitly or explicitly combined in assessments, making it difficult to compare across studies.

Heterogeneity indices are an important aspect of assessing ethnic/racial settings, but they may not be useful in all contexts. For example, school classes in European countries are often highly heterogeneous with a wide range of different ethnic groups. Heterogeneity indices lack precision in those contexts, as a low score on the Simpson Index might mean that a particular 
student is predominantly surrounded by co-ethnics or by other-ethnics (Thijs, Verkuyten, \& Grundel, 2014). In truly heterogeneous contexts, these indices would not be very informative or applicable if they were based on specific ethnic groups. Here we can see how heterogeneity can interact with differentiation, as the meaning and relevance of groups can vary in different contexts. For example, proportion of minority/immigrant children has been used in contexts where this distinction is more culturally relevant than ethnicity, per se (e.g., Vervoort, Scholte, \& Overbeek, 2010). This point highlights the importance of assessing heterogeneity in a way that is suitable to the specific context of interest.

\section{Dimension 4: Proximity of the Setting}

The fourth dimension of our framework, proximity, refers to the immediacy of the setting, or from a social ecological perspective (Bronfenbrenner, 1979), how close the person is to the setting of interest. The majority of studies have assessed ethnic/racial settings in immediate settings, at the micro-system level, in terms of the other people present at a given moment (Yip, 2005), peer groups (Yip et al., 2010), classrooms (Thijs, Verkuyten, \& Grundel, 2014), schools (Brittian, Umaña-Taylor, \& Derlan, 2013), and neighborhoods (Juang \& Nguyen, 2010; White, Updegraff, Umaña-Taylor, Zeiders, Perez-Brena, \& Burleson, in press). The concept of egohoods has been proposed as a distance-based measure that allows for overlapping, personcentered definitions of proximity (vs. distinct census tracts, for example; Hipp \& Boessen, 2013). Only a few studies have addressed ethnic/racial settings and ERI in settings on more distal levels such as city (Gee et al., 2006), state (Umaña-Taylor \& Shin, 2007) or country (Virta, Sam, \& Westin, 2004). Other fields such as sociology have looked into contextual diversity in more detail. For example, a review of the relation between ethnic/racial diversity and social cohesion found that varying levels of geographic proximity (country, regional, municipality, regional and 
neighborhood) at which diversity was measured (heterogeneity) was not consistently linked with social cohesion; rather, the links depended on the level of proximity (van der Meer \& Tolsma, 2014). Because individuals' experiences are shaped not only by the immediate surroundings but also by the larger social settings and contexts in which they live, assessing ethnic/racial settings at different levels in relation to ERI is desirable (Bronfenbrenner, 1979).

Proximal settings should be more influential to development than more distal settings because in proximal settings individuals are directly interacting with those around them (Bronfenbrenner, 1979). It can be difficult, at times, to determine which setting is more proximal than another. For example, both classroom level and city level are potentially proximal, as they both involve direct interaction. However, as argued by Graham et al. (2009) the more proximal setting is the one in which there is higher likelihood of sustained interaction. To be sure, which setting is "more" proximal is less important than the idea that assessing density at multiple levels of proximity would be a valuable addition for ERI researchers.

Echoing a consistent theme, the few studies that assess multiple nested levels of settings offer inconclusive results on the importance and outcome of proximity. For example, Seaton and Yip (2009) found that for African American youth, increased heterogeneity (the probability that two randomly selected students are from different ethnic /racial groups) at the more proximal school level, was associated with increased perceptions of cultural discrimination (defined as perceptions that the dominant group has negative beliefs towards Black culture) whereas neighborhood heterogeneity was only marginally related and was associated with decreased perceptions of cultural discrimination. Juvonen, Nishina, and Graham (2006) found that for African American and Latino youth, increased heterogeneity at both classroom and school levels was related to perceptions of greater safety and social satisfaction. But a social network study 
found no effects of classroom density (proportion of ethnic majority and ethnic minority students) on social discrimination, while neighborhood density was related to discrimination (Vermeij, van Duijn, \& Baerveldt, 2009). These findings are also difficult to synthesize, as the first two are studies of Latino and African American high school (Seaton \& Yip, 2009) and middle school (Juvonen et al., 2006) students in the US and the third was a study of ethnicallydiverse secondary school students in the Netherlands. Further, proximity of settings was combined with the heterogeneity and differentiation dimensions in the US and Dutch study in different ways.

An additional challenge to understanding how differing proximities of ethnic/racial settings are related to ERI can be seen when incorporating the first dimension of our framework, perspective. All of the work described above relied on objective measures of density. As we have argued, it is critical to also consider the subjective perspective. This can be captured using indepth qualitative (such as ethnographic) analyses of varying settings. Nibbs' (2003) analysis of Hmong immigrants to a large and diverse urban city (Dallas, Texas) versus small, homogenous town (Gammertingen, Germany) suggests that each level of proximity—from neighborhoods in communities where intimate relationships form, to more distal state or country levels-relate, at least indirectly to the development, form, and strength of Hmong individuals' ethnic identity. Country-level concentration (there are small percentages of Hmong in each country relative to the population size) may indirectly impact ethnic identity by prompting Hmong individuals to seek out Hmong communities and connections globally in order to maintain ties to their heritage culture. Ethnographic analyses offer another rich perspective beyond a multilevel quantitative analysis to understand the contributions of density by proximity.

\section{Integrating the Dimensions: Implications for Design and Analysis}


We have described four key aspects of ethnic/racial settings that have been studied in relation to ERI: perspective of density (subjective versus objective), differentiation (who is in the in-group versus out-group), heterogeneity (how diverse is the setting), and proximity (how directly are individuals in contact with the setting). Studies frequently include objective measures of ethnic/racial settings (e.g., Census Tract data), but the available evidence indicates that subjective measures should be used as well. Differentiation has often been calculated based on group boundaries defined in a variety of ways: by specific ethnic group, migration status, racial group, minority versus majority group, and People of Color versus not. In contrast, heterogeneity has been measured more consistently using Simpson’s Index. Finally, most studies consider only one level of proximity, ranging from the people around you, classroom, school, university, neighborhood, city, city type (urban versus suburban), city district, county, region (e.g., coast versus highland), state, and country. When considering the different ways in which each of the four dimensions can be defined and combined, these variations in focus and measurement of each dimension render it difficult to come to clear conclusions regarding how ethnic/racial settings relate to ERI. Thus, it is currently difficult to develop a cumulative understanding of how, when, and why ethnic/racial settings matter, because the definitions are highly inconsistent across studies. Importantly, these different configurations exist independent of us calling attention to the four different dimensions--they represent the current state of the literature.

We strongly recommend that interested researchers pay close attention to the definitional variations of the four dimensions, and carefully consider which aspects to include when planning their studies. But how can researchers be more intentional about which dimension to focus on and how to define them? Here we consider how the dimensions may be combined (both within 
and across dimensions) and what research questions could follow. Researchers could look more closely within each dimension, to see for instance, if subjective versus objective perceptions of settings matter more for levels and correlates of ERI, or to test whether classroom density versus neighborhood or city density matter more to ERI. Because densities in two settings can influence and moderate one another, researchers could examine the same dimension of density across settings. For instance, Latino adolescents who lived in high concentrated immigrant communities (residential neighborhoods) but had neighbors who were more exposed to more diverse nonresidential neighborhoods (i.e,. spent more time in other neighborhoods that had different levels of immigrant concentration), reported greater alcohol use compared to those adolescents living in high concentrated immigrant communities with neighbors who were less exposed to diverse non-home residential neighborhoods (Jackson, Browning, Krivo, Kwan, \& Washington, 2016). It is plausible that densities in multiple settings matter for ERI as well. Adolescents moving between or exposed to settings that are similar in ethnic densities may be reinforced in their ERI while those navigating very different densities in multiple settings may be reinforced for some aspects of ERI and not others. Choosing which layers within the specific dimension to focus on will, of course, depend on the research question, but a deeper examination within a dimension will help to address the question of relative importance that can be so vital moving forward.

Studies could also aim towards comparing across multiple dimensions. For example, Graham et al.'s (2009) study distinguished the type of low heterogenous setting by examining heterogeneity and differentiation (differentiating ethnic density based on same-ethnic group, i.e., proportion of Latino and African American adolescents). That is, knowing that a setting is low on heterogeneity (e.g., a classroom has only two ethnic groups) does not tell us if students are part of the ethnic group that is the majority or the minority. Thus, the researchers distinguished 
three settings: a low diverse classroom where the student is the ethnic minority, a low diverse classroom where the student is the ethnic majority, and a high diverse classroom where there is no ethnic majority. This combination of both dimensions showed that students in each of the three settings held different patterns of attributions related to peer victimization. Therefore, combining heterogeneity and differentiation yielded important information that focusing solely on one dimension would have missed. Systematically testing combinations of dimensions will be important to pinpoint what dimension(s) are important for what outcomes.

Although targeting within-dimension and across-dimension comparisons can be fruitful, it is critical to recognize that the close interconnection of the four dimensions means that any across-dimension analysis will necessarily involve some within-dimension assumptions or default definitions (and vice versa). For example, in terms of within-dimension definitions, the Graham et al. (2009) study defined differentiation as pan-ethnic groups (Latinos and African Americans), but those groups could have been defined at a more granular level (by specific ethnicity, generational status, etc.). The study also made across-dimension assumptions, fixing the dimension of perspective at the objective level and proximity at the classroom level. This example highlights how all four dimensions are always relevant and defined for any given study of ethnic/racial settings. What varies is what researchers choose to actively define and examine, and where they train their conceptual focus. Given the omni-relevance of all four dimensions, researchers should always strive to actively define each one, and in such a way that is optimal for their research question.

Finally, it is worth briefly considering the types of data that are necessary in order to fully realize the framework for ethnic/racial settings that we have laid out. As with any study, the exact nature of the data necessary will be dependent on the research question. Although large 
samples of adolescents and other raters (teachers, peers, parents) sampled across a large number of contextual units (classrooms, schools, neighborhoods, etc) is the gold standard, it is certainly not required. Each dimension has its own set of design considerations that can be enacted without too much effort. For perspective, the implication is to be sure to collect some form of subjective measure of density from the participants themselves, to pair with the objective indicators that are readily available from official records. Doing this does not require any additional resources or sample sizes beyond what is typically done--past studies on density and ERI could have easily included such a measure had the researchers thought of it beforehand (e.g., Juang et al., 2006; Umaña-Taylor, 2004; Syed et al., 2007). Differentiation may require collecting larger, more specific samples than the pan-ethnic groups that are often used in ERI research, as for example Syed and Juan's (2012) study indicated that the largest contextual associations were observed when estimated at the ethnic-specific level (e.g., Vietnamese Americans vs. Asian Americans). Heterogeneity requires attending to the group structure beyond only the target group, and can be assessed in both objective and subjective terms. Finally, adequately addressing proximity poses perhaps the greatest challenge. Studies of ethnic/racial settings and ERI have tended to conceptualize settings at a rather distal level (e.g, school-level density in Umaña-Taylor, 2004). More proximal investigations are needed, but are intensive. For example, Juvonen, Kogachi, and Graham (2017) examined students’ course schedules and assessed the heterogeneity of each of their four core courses (math, science, English, and social studies) to develop a person-centered index of the school setting through the day. Such an approach is innovative and valuable, but also clearly resource-intensive and requires a level of access to schools that not all researchers enjoy. In sum, some aspects of our proposed framework 
can be enacted fairly easily, whereas others may be more difficult, but all are well within reason for researchers interested in ethnic/racial settings and ERI.

\section{Conclusions and the Future of Density and ERI}

Most researchers likely believe, explicitly or implicitly, that ethnic/racial settings matter for ERI development. This belief, supported by the core theoretical frameworks, has not translated into rigorous empirical analysis. The existing research is characterized by inconsistent methods and findings. Taking the dimensions of our framework together-perspective, differentiation, heterogeneity, and proximity_yields a large matrix of potential definitions of ethnic/racial settings. If researchers haphazardly select one cell from that matrix to use in their studies (e.g., objective assessment of Asian American neighborhood density in a mostly White city vs. subjective assessment of Asian American city density in a high diverse city), then it renders the knowledge incomplete, and synthesis across studies impossible. The purpose of introducing our new framework is to encourage researchers to be more intentional in their study of ethnic/racial settings so that we can begin to develop cumulative knowledge of it and how it is related to ERI development.

Of course, the new framework alone is not sufficient, as a number of additional issues must also be considered. First, an important issue that was beyond our purview in the current article was the conceptualization of ERI itself. ERI is not a monolithic construct, and is theorized from developmental, personality, and social psychological perspectives (Umaña-Taylor et al., 2014). The developmental model of ERI, which consists of the broad processes of exploration and commitment, is measured using a wide array of scales and subscales, making it difficult to develop cumulative knowledge (Schwartz et al., 2014). Sellers and colleagues’ (1997) multidimensional model of racial identity (MMRI) incorporates contextual sensitivity into the 
model, and yet relatively little research has examined how the components of the model— salience, centrality, regard, and ideology—relate to density (but see Yip, 2005, for an exception). Upon clarification of the concept of ethnic/racial settings themselves—-the primary objective of the current article-ERI theorists and researchers must work to develop specific hypotheses about how different dimensions of density (alone or in concert) are associated with the relative strength of different ERI dimensions or how they moderate associations between ERI and important psychological outcomes. Again, as we have reviewed in this paper there are many papers that do this, but they do not do it with sufficient conceptual clarity around ethnic/racial settings. We hope that the current framework helps researchers do just that.

An important area of future research is to sort out the direction of associations between ERI and ethnic/racial settings, as it is often assumed that that the direction flows from settings to ERI. However, it is plausible that those with stronger ERI may select neighborhoods with greater density, for example. For children and adolescents, it is possible that their parents sought out a neighborhood with greater density, and thus the association between density and ERI can be accounted for by parent effects, such as cultural socialization (Hughes et al., 2006).

This draws attention to another area for future work: what explains the association between ethnic/racial settings and ERI? That is, ethnic/racial settings serve as a proxy for a variety of potentially relevant factors (e.g., co-ethnic and inter-ethnic relations, cultural resources) which themselves should be measured to achieve greater specificity. Greater heterogeneity at both classroom and schools levels are related to adolescent perceptions of greater safety and social satisfaction (Juvonen, et al., 2006), which may, in turn, have implications for the development of ERI by providing a safe space for exploration. Greater concentration of co-ethnics in the neighborhood is related to adolescent reports of lower peer 
discrimination as well as greater ERI exploration (White et al., 2017). Indeed, it is important to theorize and address more specifically what is happening within these dimensions.

Divergent findings for proximity, for instance, may be due to studies focusing more on measuring density of the setting with counts of people, without assessing the quality of interactions between people in the particular setting (see Sadler \& Devos, 2017). A student may experience predominantly positive interactions in the classroom, but once outside the classroom and interacting with people in the city, may be targeted for discrimination. The potential experiential differences at varying levels of proximity is one layer that should be built upon to address the quality of interactions to understand the consequences for ERI. Importantly, that settings serve as a proxy for more dynamic contextual and interactional process does not mean that it is unimportant to study in its own right. Settings can serve as a broader structure for a given context, enabling specific patterns of behavior. For example, being in a classroom with a high proportion and heterogeneity of other-ethnic peers affords more opportunities for intergroup contact (Verkuyten \& Thijs, 2002). Thus, knowing both the structural conditions and quality of interactions allows for exploration into whether specific settinhgs are necessary for certain behaviors to happen.

Developmentally, future work should bring greater consideration to the role of time and change for experiences of ethnic/racial settings (see Graham, 2016, for more detail). Objectively, as adolescents transition through different schools they will encounter differing ethnic/racial settings (Douglass et al., 2014). Generally, the racial/ethnic composition of schools changes from elementary to high school, with increased heterogeneity as smaller, homogeneous schools are merged to create larger, more heterogeneous schools (Orfield, 2001). Subjectively, perceptions of densities can also change. For instance, as adolescents' ERI becomes stronger, they may 
spend more time with co-ethnic members and subsequently perceive their neighborhoods to have more co-ethnic members. Once again, the dimension of perspective is key to understanding stability and change in the different ethnic/racial setting dimensions.

Finally, a central take home message and future consideration is that the context of the study must determine how ethnic/racial settings are assessed in terms of the different model dimensions. This is particularly important as ERI research is increasingly understood in global terms. The valuable progress made by the ERI Study Group was confined to the U.S. context. As we attempted to highlight, some of the basic understandings that are taken as "givens" in the U.S. (e.g., the use of particular labels, the meaningfulness of pan-ethnic groups) do not translate to different cultural contexts. As we continue to advance ERI development as a global and contextual psychological phenomenon, awareness of the cultural context of ERI is critical. 


\section{References}

Alesina, A., Devleeschauwer, A., Easterly, W., Kurlat, S., \& Wacziarg, R. (2003).

Fractionalization. Journal of Economic Growth, 8(2), 155-194.

Ashmore, R. D., Deaux, K., \& McLaughlin-Volpe, T. (2004). An Organizing Framework for Collective Identity: Articulation and Significance of Multidimensionality. Psychological Bulletin, 130(1), 80-114.

Bécares, L., Shaw, R., Nazroo, J., Stafford, M., Albor, C., Atkin, K., . . .Pickett, K. (2012). Ethnic density effects on physical morbidity, mortality, and health behaviors: A systematic review of the literature. American Journal of Public Health, 102(12), 33-66.

Bellmore, A.D., Nishina, A., Witkow, M.R., Graham, S., \& Juvonen, J. (2007). The influence of classroom ethnic composition on same- and other-ethnicity peer nominations in middle school. Social Development, 16(4), 720-740.

Bellmore, A., Nishina, A., You, J.-i., \& Ma, T.-L. (2012). School context protective factors against peer ethnic discrimination across the high school years. American Journal of Community Psychology, 49(1-2), 98-111.

Benner, A., \& Graham, S. (2013). The antecedents and consequences of racial/ethnic discrimination during adolescence: Does the source of discrimination matter? Developmental Psychology, 49, 1602-1613.

Brittian, A. S., Umaña-Taylor, A. J., \& Derlan, C. L. (2013). An examination of biracial college youths' family ethnic socialization, ethnic identity, and adjustment: Do self-identification labels and university context matter? Cultural Diversity and Ethnic Minority Psychology, 19(2), 177-189. 
Bronfenbrenner, U. (1979). The Ecology of Human Development: Experiments by Nature and Design. Cambridge, MA: Harvard University Press.

Bronfenbrenner, U., \& Ceci, S. J. (1994). Nature-nurture reconceptualized in developmental perspective: A bioecological model. Psychological Review, 101(4), 568-586.

Brown, C. S. (2017). School context influences the ethnic identity development of immigrant children in middle childhood. Social Development.

Budescu, D. V., \& Budescu, M. (2012). How to Measure Diversity When You Must. Psychological Methods, 17(2), 215-227. doi: 10.1037/a0027129

Douglass, S., Yip, T., \& Shelton, J. N. (2014). Intragroup contact and anxiety among ethnic minority adolescents: Considering ethnic identity and school diversity transitions. Journal of Youth and Adolescence, 43(10), 1628-1641.

Erikson, E. H. (1968). Identity, youth and crisis. NY: W. W. Norton Company.

Fauth, R. C., Roth, J. L., \& Brooks-Gunn, J. (2007). Does the neighborhood context alter the link between youth's after-school time activities and developmental outcomes? A multilevel analysis. Developmental Psychology, 43(3), 760.

García Coll, C., Crnic, K., Lamberty, G., Wasik, B. H., Jenkins, R., Garcia, H. V., \& McAdoo, H. P. (1996). An integrative model for the study of developmental competencies in minority children. Child Development, 67(5), 1891-1914.

Gee, G. C., Chen, J., Spencer, M., See, S., Kuester, O., Tram, D., \& Takeuchi, D. (2006). Social Support as a Buffer for Perceived Unfair Treatment Among Filipino Americans: Differences Between San Francisco and Honolulu. American Journal of Public Health, 96(4), 677-684. 
Gjerde, P. F. (2004). Culture, power, and experience: Toward a person-centered cultural psychology. Human Development, 47(3), 138-157.

Graham, S. (2016). Commentary: The Role of Race/Ethnicity in a Developmental Science of Equity and Justice. Child Development, 87(5), 1493-1504.

Graham, S., Bellmore, A., Nishina, A., \& Juvonen, J. (2009). 'It must be me': Ethnic diversity and attributions for peer victimization in middle school. Journal of Youth and Adolescence, 38(4), 487-499.

Graham, S., Munniksma, A., \& Juvonen, J. (2014). Psychosocial benefits of cross-ethnic friendships in urban middle schools. Child Development, 85(2), 469-483.

Hipp, J. R., \& Boessen, A. (2013). Egohoods as waves washing across the city: A new measure of “neighborhoods”. Criminology, 51(2), 287-327.

Hochschild, J.L. (2005). Looking ahead: Racial trends in the United States. Daedalus, 134(1), 70-81.

Hughes, D., Rodriguez, J., Smith, E. P., Johnson, D. J., Stevenson, H. C., \& Spicer, P. (2006). Parents' ethnic-racial socialization practices: A review of research and directions for future study. Developmental Psychology, 42(5), 747-770.

Jackson, A. L., Browning, C. R., Krivo, L. J., Kwan, M. P., \& Washington, H. M. (2016). The Role of Immigrant Concentration Within and Beyond Residential Neighborhoods in Adolescent Alcohol Use. Journal of Youth and Adolescence, 45 (1), 17-34.

Juang, L. P., \& Alvarez, A. A. (2011). Discrimination and adjustment among Chinese American adolescents: Family conflict and family cohesion as vulnerability and protective factors. American Journal of Public Health, 100(12), 2403-2409. 
Juang, L. P., \& Nguyen, H. H. (2010). Ethnic identity among Chinese-American youth: The role of family obligation and community factors on ethnic engagement, clarity, and pride. Identity: An International Journal of Theory and Research, 10(1), 20-38.

Juang, L. P., Nguyen, H. H., \& Lin, Y. (2006). The Ethnic Identity, Other-Group Attitudes, and Psychosocial Functioning of Asian American Emerging Adults From Two Contexts. Journal of Adolescent Research, 21(5), 542-568.

Juvonen, J., Kogachi, K., \& Graham, S. (2017). When and how do students benefit from ethnic diversity in middle school? Child Development.[online first]

Juvonen, J., Nishina, A., \& Graham, S. (2006). Ethnic Diversity and Perceptions of Safety in Urban Middle Schools. Psychological Science, 17(5), 393-400.

Kubrin, C. E., \& Weitzer, R. (2003). New directions in social disorganization theory. Journal of Research in Crime and Delinquency, 40(4), 374-402.

Kumar, R., Seay, N., \& Karabenick, S. A. (2015). Immigrant Arab adolescents in ethnic enclaves: Physical and phenomenological contexts of identity negotiation. Cultural Diversity and Ethnic Minority Psychology, 21(2), 201-212.

Maly, M. (2000). The Neighborhood Diversity Index: A complementary measure of racial residential settlement. Journal of Urban Affairs, 22, 37-47.

Marcia, J.E. (1966). Development and validation of ego identity status. Journal of Personality and Social Psychology, 3 , 551-558.

Massey, D. S., \& Denton, N. (1988). The dimensions of residential segregation. Social Forces, 67, 281-315.

Moody, J. (2001). Race, school integration, and friendship segregation in America. American Journal of Sociology, 107(3), 679-716. 
Nibbs, F. (2003). Belonging: The social dynamics of fitting in as experienced by Hmong refugees in Germany and Texas. Durham, NC: Carolina Academic Press.

Orfield, G. (Ed.). (2001). Diversity challenged: Evidence on the impact of affirmative action. Cambridge, MA: Harvard Education Publishing Group.

Oyserman, D., \& Yoon, K. (2009). Neighborhood Effects on Racial-Ethnic Identity: The Undermining Role of Segregation. Race and Social Problems, 1 (2), 67-76.

Phinney, J. S. (1990). Ethnic identity in adolescents and adults: Review of research. Psychological Bulletin, 108(3), 499-514.

Phinney, J. S., Ferguson, D. L., \& Tate, J. D. (1997). Intergroup attitudes among ethnic minority adolescents: A causal model. Child Development, 68(5), 955-969.

Phinney, J. S., Romero, I., Nava, M., \& Huang, D. (2001). The role of language, parents, and peers in ethnic identity among adolescents in immigrant families. Journal of Youth and Adolescence, 30(2), 135-153.

Raudenbush, S. W., \& Sampson, R. J. (1999). Ecometrics: toward a science of assessing ecological settings, with application to the systematic social observation of neighborhoods. Sociological Methodology, 29(1), 1-41.

Rivas-Drake, D., Seaton, E. K., Markstrom, C., Quintana, S., Syed, M., Lee, R. M., .. Yip, T. (2014). Ethnic and racial identity in adolescence: Implications for psychosocial, academic, and health outcomes. Child Development, 85(1), 40-57.

Rivas-Drake, D., Syed, M., Umaña-Taylor, A., Markstrom, C., French, S., Schwartz, S. J., \& Lee, R. (2014). Feeling good, happy, and proud: A meta-analysis of positive ethnic-racial affect and adjustment. Child Development, 85(1), 77-102. 
Roberts, R. E., Phinney, J. S., Masse, L. C., Chen, Y. R., Roberts, C. R., \& Romero, A. (1999). The structure of ethnic identity of young adolescents from diverse ethnocultural groups. The Journal of Early Adolescence, 19(3), 301-322.

Rucker, J. M., Neblett, E. W., Jr., \& Anyiwo, N. (2014). Racial identity, perpetrator race, racial composition of primary community, and mood responses to discrimination. Journal of Black Psychology, 40(6), 539-562.

Ruvalcaba, O., Rogoff, B., López, A., Correa-Chávez, M., \& Gutiérrez, K. (2015). Children's avoidance of interrupting others’ activities in requesting help: Cultural aspects of considerateness. Advances in child development and behavior, 49, 185-205.

Sadler, M., \& Devos, T. (2017). Pluralistic or exclusive? Context ethnic diversity dimensions predict implicit conceptions of national identity. Manuscript submitted for publication.

Santos, C. E., Kornienko, O., \& Rivas-Drake, D. (2017). Peer influence on ethnic-racial identity development: A multi-site investigation. Child Development, 88(3), 725-742.

Schachner, M. K., Noack, P., Van de Vijver, F. J., \& Eckstein, K. (2016). Cultural diversity climate and psychological adjustment at school—equality and inclusion versus cultural pluralism. Child Development, 87(4), 1175-1191.

Schwartz, S. J., Syed, M., Yip, T., Knight, G. P., Umaña-Taylor, A. J., Rivas-Drake, D., \& Lee, R. M. (2014). Methodological issues in ethnic and racial identity research with ethnic minority populations: Theoretical precision, measurement issues, and research designs. Child Development, 85(1), 58-76.

Seaton, E. K., Quintana, S., Verkuyten, M., \& Gee, G. C. (2017). Peers, policies, and place: The relation between context and ethnic/racial identity. Child Development, 88(3), 683-692. 
Seaton, E. K., \& Yip, T. (2009). School and neighborhood contexts, perceptions of racial discrimination, and psychological well-being among African American adolescents. Journal of Youth and Adolescence, 38(2), 153-163.

Sellers, R. M., Rowley, S. A. J., Chavous, T. M., Shelton, J. N., \& Smith, M. A. (1997). Multidimensional Inventory of Black Identity: A preliminary investigation of reliability and construct validity. Journal of Personality and Social Psychology, 73(4), 805-815.

Simpson, E. H. (1949). Measurement of diversity. Nature, 163, 688-688.

Stevenson, H. C., McNeil, J. D., Herrero-Taylor, T., \& Davis, G. Y. (2005). Influence of perceived neighborhood diversity and racism experience on the racial socialization of Black youth. Journal of Black Psychology, 31(3), 273-290.

Svensson, Y., Burk, W. J., Stattin, H., \& Kerr, M. (2012). Peer selection and influence of delinquent behavior of immigrant and nonimmigrant youths: Does context matter? International Journal of Behavioral Development, 36(3), 178-185.

Syed, M. (2010). Developing an integrated self: Academic and ethnic identities among ethnically-diverse college students. Developmental Psychology, 46(6), 1590-1604.

Syed, M., Azmitia, M., \& Phinney, J. S. (2007). Stability and change in ethnic identity among Latino emerging adults in two contexts. Identity: An International Journal of Theory and Research, 7(2), 155-178.

Syed, M., \& Juan, M. J. D. (2012). Discrimination and psychological distress: Examining the moderating role of social context in a nationally representative sample of Asian American adults. Asian American Journal of Psychology, 3(2), 104-120. 
Tajfel, H., \& Turner, J. C. (1986). The social identity theory of intergroup behaviour. In S. Worchel \& W. G. Austin (Eds.), Psychology of intergroup relations (pp. 7-24). Chicago, IL: Nelson-Hall.

Teo, T. (2009). Psychology without Caucasians. Canadian Psychology/Psychologie canadienne, 50(2), 91.

Thijs, J., Verkuyten, M., \& Grundel, M. (2014). Ethnic classroom composition and peer victimization: The moderating role of classroom attitudes. Journal of Social Issues, 70(1), 134-150.

Titzmann, P. F., \& Silbereisen, R. K. (2009). Friendship homophily among ethnic German immigrants: A longitudinal comparison between recent and more experienced immigrant adolescents. Journal of Family Psychology, 23(3), 301-310.

Umaña-Taylor, A. (2004). Ethnic identity and self-esteem: examining the role of social context. Journal of Adolescence, 27(2), 139-146.

Umaña-Taylor, A. J., \& Shin, N. (2007). An examination of ethnic identity and self-esteem with diverse populations: Exploring variation by ethnicity and geography. Cultural Diversity \& Ethnic Minority Psychology, 13(2), 178-186.

Umaña-Taylor, A. J., Quintana, S. M., Lee, R. M., Cross, W. E., Rivas-Drake, D., Schwartz, S. J., . . Seaton, E. (2014). Ethnic and racial identity during adolescence and into young adulthood: An integrated conceptualization. Child Development, 85(1), 21-39.

Van der Meer, T., \& Tolsma, J. (2014). Ethnic Diversity and Its Effects on Social Cohesion. Annual Review of Sociology, 40, 459-78.

Verkuyten, M. (2016). Further conceptualizing ethnic and racial identity research: The social identity approach and its dynamic model. Child Development, 87(6), 1796-1812. 
Verkuyten, M., \& Thijs, J. (2002). Racist victimization among children in the Netherlands: The effect of ethnic group and school. Ethnic and Racial Studies, 25, 310 -331.

Vermeij, L., van Duijn, M. A. J., \& Baerveldt, C. (2009). Ethnic segregation in context: Social discrimination among native Dutch pupils and their ethnic minority classmates. Social Networks, 31(4), 230-239.

Vervoort, M., Flap, H., \& Dagevos, J. (2011). The Ethnic Composition of the Neighbourhood and Ethnic Minorities’ Social Contacts: Three Unresolved Issues. European Sociological Review, 27(5), 586-604.

Vervoort, M. H. M., Scholte, R. H. J., \& Overbeek, G. (2010). Bullying and victimization among adolescents: The role of ethnicity and ethnic composition of school class. Journal of Youth and Adolescence, 39(1), 1-11.

Virta, E., Sam, D. L., \& Westin, C. (2004). Adolescents with Turkish background in Norway and Sweden: A comparative study of their psychological adaptation. Scandinavian Journal of Psychology, 45(1), 15-25.

Way, N., \& Rogers, O. (2015). '[T]hey say Black men won't make it, but I know I'm gonna make it': Ethnic and racial identity development in the context of cultural stereotypes. In K. C. McLean, M. Syed, K. C. McLean \& M. Syed (Eds.), The Oxford handbook of identity development. (pp. 269-285). New York, NY, US: Oxford University Press.

White, R., Knight, G. P., Jensen, M., \& Gonzales, N. A. (2017). Ethnic socialization in neighborhood contexts: Implications for ethnic attitude and identity development among Mexican-origin adolescents. Child Development. 
White, R.M.B., Updegraff, K.A., Umaña-Taylor, A.J., Zeiders, K.H., Perez-Brena, N., \& Burleson, E. (in press). Neighborhood and school ethnic structuring and cultural adaptations among Mexican-origin adolescents. Developmental Psychology.

Yip, T. (2005). Sources of Situational Variation in Ethnic Identity and Psychological WellBeing: A Palm Pilot Study of Chinese American Students. Personality and Social Psychology Bulletin, 31(12), 1603-1616.

Yip, T., Seaton, E. K., \& Sellers, R. M. (2010). Interracial and intraracial contact, school-level diversity, and change in racial identity status among African American adolescents. Child Development, 81(5), 1431-1444. 
Table 1

Description of the four dimensions of ethnic-racial settings relevant for ethnic-racial identity

\begin{tabular}{|c|c|c|}
\hline Dimension & Description & Examples of studies and measurement \\
\hline \multirow[t]{2}{*}{ Perspective } & $\begin{array}{l}\text { Adopting an objective or subjective } \\
\text { perspective of density }\end{array}$ & $\begin{array}{l}\text { Setting measured objectively with proportion of Latinos in school } \\
\text { (Umana Taylor, 2004) }\end{array}$ \\
\hline & & $\begin{array}{l}\text { Setting measured by subjective perception of ethnic density of } \\
\text { neighborhood (Phinney, Ferguson, \& Tate, 1997) }\end{array}$ \\
\hline Differentiation & $\begin{array}{l}\text { How the ethnic group of reference is } \\
\text { defined in a setting }\end{array}$ & $\begin{array}{l}\text { Setting defined by three levels of differentiation --ethnic-specific, } \\
\text { pan-ethnic, and People of Color (Syed \& Juan, 2012) }\end{array}$ \\
\hline Heterogeneity & $\begin{array}{l}\text { Degree of diversity of different ethnic } \\
\text { groups in the setting }\end{array}$ & $\begin{array}{l}\text { Diversity of ethnic density measured by Simpson's index } \\
\text { (Juvonen, Nishina, \& Graham, 2006) }\end{array}$ \\
\hline Proximity & $\begin{array}{l}\text { Distance between the individual and the } \\
\text { setting }\end{array}$ & $\begin{array}{l}\text { Setting defined by the people around you at a given moment (Yip, } \\
\text { 2005), peer groups (Yip et al., 2010), classrooms (Thijs, Verkuyten, } \\
\text { \& Grundel, 2014), and schools (Brittian, Umaña-Taylor, \& Derlan, } \\
\text { 2013) }\end{array}$ \\
\hline
\end{tabular}

